\title{
14. Issues and Prospects for the Restructuring of China's Steel Industry
}

\author{
Haimin Liu and Ligang Song
}

\section{Introduction}

China's steelmaking capacity has expanded rapidly over the reform period and especially since the beginning of the twenty-first century. The scale of that expansion is unprecedented in the history of industrialisation in Europe, North America and East Asia. This is a result of the fact that the rapid growth of the Chinese economy was driven by an investment-led growth model centring on the development of heavy industries such as machinery and transport equipment manufacturing, and also an unprecedented scale of urbanisation with associated demand for housing and infrastructure such as roads, railways, ports, airports and utilities.

China's annual production of crude steel reached 804 million tonnes in 2015, 6.3 times higher than the total production in 2000. It accounts for nearly 50 per cent of the total global steel output, rising from only 15 per cent of the total at the end of the previous century. This follows from China becoming the largest steel producer in the world two decades ago, in 1996.

The rapid expansion of the industry induced a parallel increase in demand for iron ore, leading to soaring prices for iron ore on world markets. In the Asian market, the price of iron ore increased from US\$13.8/t in 2003 to US\$96.8/t in 2014, after peaking at US\$187.2/t in 2011 (Hurst 2015). These dramatic shifts in iron ore prices underscore the so-called super resource boom in the period 2003-13. During this decade, the Chinese steel industry consumed more than 60 per cent of total global production of iron ore. Its dependency on imported iron ore (the ratio between imports and domestic production) also reached unprecedented levels.

The rapid expansion in the domestic production of steel products transformed China into a net exporter of steel products in 2006, and it is now the largest exporter of those products in the world. China exported more than 100 million tonnes of steel products to the world market in 2015-50 per cent larger than the entire amount of steel produced in the United States the same year (Sanderson 2015). These exports have helped to ease overcapacity pressures in China's domestic 
industrial sector. At the same time, rising dependence on global sales has increased related trade tensions with other steel-producing countries. In 2015, there were 37 cases relating to antidumping and anti-subsidy launched against China by major steel-producing countries.

Since the onset of the Global Financial Crisis (GFC) in 2008, China's annual economic growth rate has progressively slowed. The steel industry is prone to cyclical changes alongside other industries including cement and aluminium, which means that the sector has become trapped in a cycle of excess capacity. In turn, in 2014-15, the price of steel products continuously hit new lows, adding enormous pressure to domestic industrial restructuring. Having earlier lingered around breakeven point, the members of the China Iron and Steel Association (CISA) - namely, large and medium-sized steel enterprises - have as a whole incurred huge losses. Dozens of enterprises have stopped operating or will be forced into bankruptcy, highlighting the urgency for restructuring and reform of the industry.

In recent years, the focus in the restructuring of China's steel industry has been mainly on reducing the quantity of production and increasing the industry's overall technical standards. For example, the government encouraged enterprises to remove obsolete and old-fashioned equipment, to limit building new capacity, to increase exports, to develop new steel production structures via production of higher value-added products and to expand overseas projects by carrying out more foreign direct investment. These reform and restructuring measures have, however, not helped the steel industry to exit a difficult period. Instead, the overriding structural problems in the industry have deepened.

At the end of 2015, the Central Government proposed and started implementation of a strategy of 'supply-side reforms' that aimed to improve and restructure supply-side aspects of China's economy. This represents an important shift in policy focus towards dealing with the underlying structural challenges facing the economy, compared with the greater focus on demand expansion of earlier policy. Within the steel industry, the main objective of supply-side reforms is to address excess capacity through various reform measures including shutting some steel mills. In January 2016, the State Council promulgated the Advice on addressing excessive capacity and relieving hardship for the steel industry', which specifically proposed that steelmaking capacity in China should be reduced by 100-150 million tonnes in the next five years.

There is evidence also that the root causes of the problems currently facing the industry are not exclusively or even chiefly related to issues of production quantity and technology used, but rather to the operating mechanisms of the industry itself - in particular, the dual ownership structure of China's steel industry, which sees it divided roughly equally between state-owned and 
private companies. In the state-owned steel sector, there have been various market failures, including the inefficient market allocation of resources and lagging ownership reforms, plus local governments' blind strategy approaches to industry expansion that worsened the problem of overcapacity and have transformed many enterprises into 'zombie enterprises' (Liu 2013a).

It is clear that the Chinese steel industry has no choice but to further restructure and address this 'zombie companies' issue. This will only happen by deepening reform that is supported by public policy, including in terms of relocating and retraining workers whose employment may be adversely affected. Only in this way can the steel industry ultimately get back on track towards more sustainable future development.

This chapter reviews the performance of China's steel industry by analysing the underlying drivers of its recent rapid development; identifies the key challenges facing the industry amid the economic slowdown, including the causes of deteriorating performance and overcapacity; and finally, offers an outlook for the industry that could result from current restructuring programs.

\section{Twenty-first-century expansion and performance of China's steel industry}

Steel production in China witnessed explosive growth in the decade after 2000. China's rapidly growing economic size underpinned huge growth in demand for steel products, which gave impetus to the rapid growth and expansion of the industry (Song and Liu 2012). Accompanying the increase in the scale of the industry were several concurrent structural shifts. In 2006, China shifted from being a net importer of steel to become a net exporter of steel products (Table 14.1). Also in 2006, China replaced Japan as both the biggest steelexporting country and the biggest net steel-exporting country in the world.

A decade on, the latest available data (Table 14.1) reveal that Chinese imports of steel equivalent dropped to 13.9 million tonnes in 2015, from the historic peak of 45.6 million tonnes in 2003. Exports of steel equivalent in the same period increased to 120 million tonnes, up from 8.9 million tonnes. The self-sufficiency ratio of steel in China exceeded 100 per cent in 2005, and had increased to 115 per cent by 2015, as shown in the last column of Table 14.1. 


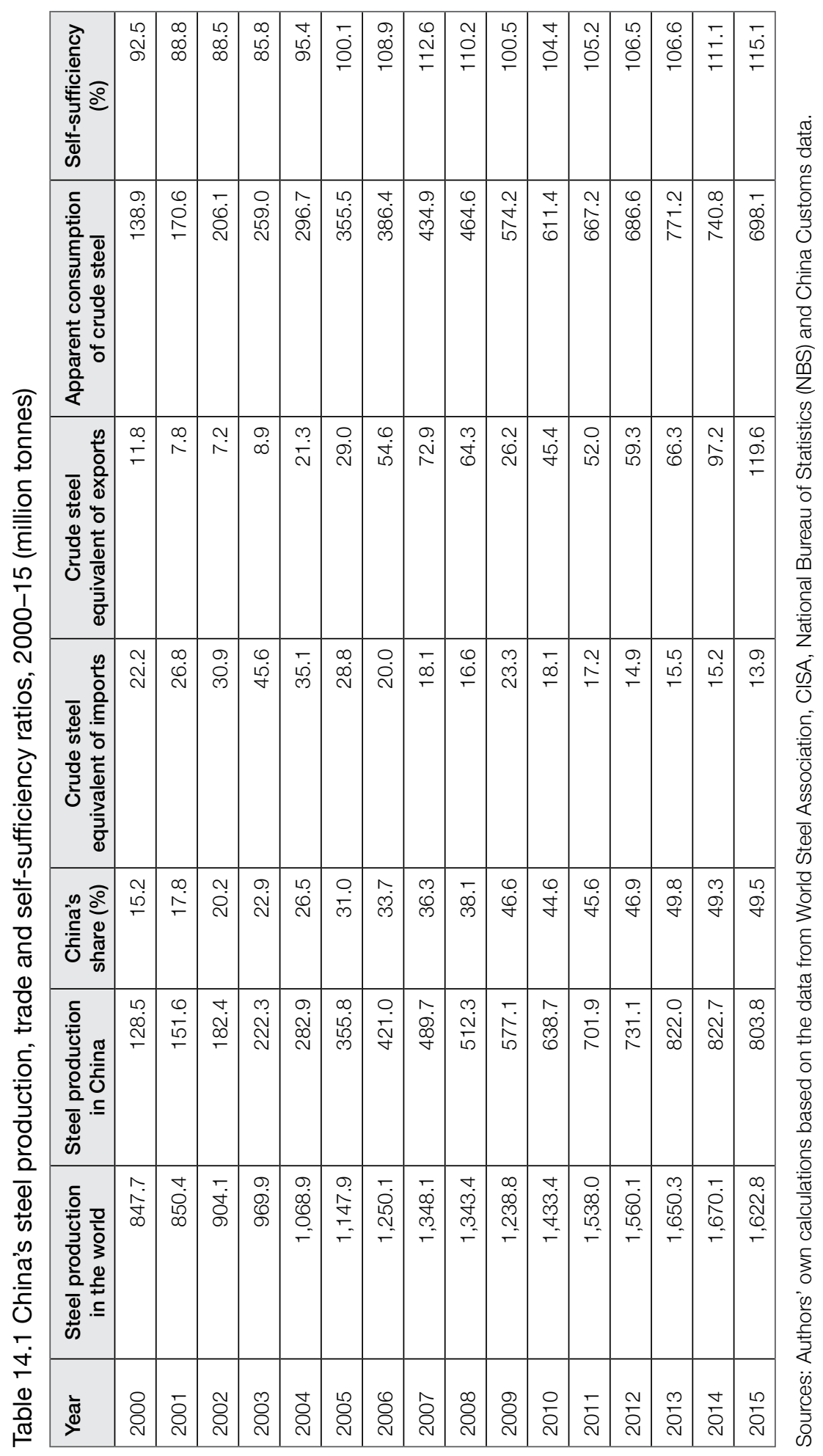


Table 14.1 highlights recent increases in domestic consumption of steel, which triggered massive investment in the industry by both the state and the private sectors, which in turn produced continually increasing volumes of steel above domestic demand, until 2015, when production levels began to fall. Domestic consumption, as Table 14.1 also shows, peaked two years before this decline in production, at 771 million tonnes in 2013. That year China produced 822 million tonnes of steel. The mismatch between peak domestic consumption and peak domestic production exacerbated overcapacity problems when, in 2015, domestic consumption declined to 698 million tonnes but domestic production did not adjust smoothly in response. Instead, domestic production stayed at 803 million tonnes. And, because over 2013-15 China accounted for nearly half of global total steel production, these numbers have in turn impacted on world steel markets (OECD 2016).

In addition to these production and consumption trends, a recent structural shift in China's steel industry means that the steel products it produces have improved in terms of both quality and variety. Table 14.2 provides data on total production, trade, apparent consumption and the self-sufficiency ratio for different varieties of steel products. Almost all varieties had, by 2015, achieved at least 100 per cent self-sufficiency. In some product areas, including rails and wheels, steel bars, medium plates, galvanised sheets (strip), seamless tubes and coated sheets (strip), there are severe overcapacity problems, as measured by very high self-sufficiency ratios. Steel companies have naturally turned to international markets and sold more than 100 million tonnes of related products in 2015. This raises questions about China's competitiveness in steel products on the world market and reactions to it by other steel-producing countries such as increasing antidumping cases against China's steel exports.

China's steel products are competitive on world markets mainly as a result of economies of scale and technical progress, as well as improvement in equipment, meaning that steel production processes are more efficient in terms of energy, water and other resource consumption per unit of output. This follows from the fact that over the past decade the Chinese Government adjusted its industrial policies in ways that led to the closure of outdated steel plants. For example, firms with iron-smelting production capacity of less than 120 million tonnes and steel smelting capacity below 90 million tonnes were forced to close. By 2016, almost all small blast furnaces (those smaller than $400 \mathrm{cu} \mathrm{m}$ ) and all small steelsmelting equipment (less than 30 tonnes capacity) had been closed. 
Table 14.2 Production, foreign trade, consumption and self-sufficiency ratio by steel product category, China, 2015 (million tonnes)

\begin{tabular}{|l|r|r|r|r|r|}
\hline Steel varieties & Production & Exports & Imports & $\begin{array}{c}\text { Apparent } \\
\text { consumption }\end{array}$ & $\begin{array}{c}\text { Self-sufficient } \\
\text { rate (\%) }\end{array}$ \\
\hline Total finished steel & 779.5 & 112.4 & 12.8 & 679.9 & 114.7 \\
\hline Rail \& wheel & 4.8 & 0.8 & 0.0 & 4.1 & 119.2 \\
\hline Large section & 14.4 & 0.9 & 0.3 & 13.7 & 104.7 \\
\hline M\&S section & 56.6 & 4.3 & 0.0 & 52.3 & 108.2 \\
\hline Steel bar & 71.3 & 31.4 & 0.5 & 40.4 & 176.7 \\
\hline Rebar & 204.3 & 0.2 & 0.0 & 204.1 & 100.1 \\
\hline Wire rod & 147.2 & 12.3 & 0.6 & 135.5 & 108.6 \\
\hline Ultra-thick plate & 7.7 & 0.1 & 0.1 & 7.7 & 100.2 \\
\hline Heavy plate & 25.4 & 0.1 & 0.3 & 25.7 & 99.0 \\
\hline Medium plate & 40.2 & 7.5 & 1.3 & 34.0 & 118.4 \\
\hline MT wide strip & 123.3 & 15.3 & 1.5 & 109.6 & 112.6 \\
\hline HR wide sheet (strip) & 62.0 & 0.2 & 0.8 & 62.5 & 99.1 \\
\hline CR wide sheet (strip) & 83.8 & 6.0 & 2.8 & 80.7 & 105.4 \\
\hline HR narrow strip & 63.6 & 0.2 & 0.1 & 63.5 & 100.2 \\
\hline CR narrow strip & 13.5 & 0.2 & 0.2 & 13.5 & 99.9 \\
\hline Galvanised sheet (strip) & 52.1 & 11.4 & 3.0 & 43.7 & 119.2 \\
\hline Coated sheet (strip) & 8.1 & 7.1 & 0.2 & 1.2 & 684.3 \\
\hline Electrical sheet & 8.8 & 0.4 & 0.5 & 8.9 & 99.1 \\
\hline Seamless tube & 28.6 & 4.5 & 0.2 & 24.2 & 118.0 \\
\hline Welded tube & 69.7 & 4.7 & 0.2 & 65.1 & 107.0 \\
\hline Others & 38.0 & 0.7 & 0.0 & 37.3 & 101.8 \\
\hline
\end{tabular}

Sources: Calculated using data from NBS, China Customs.

In addition to closing small-scale production sites, energy saving and emission reduction technologies have been widely adopted. Examples include toppressure recovery turbine technology (a device used in generating electricity at differential pressures inside a blast furnace), gas recycling, dry quenching, dry dust removal and water recycling, as well as the adoption of sulphur removal from sintering machines. The comprehensive energy consumption of the CISA members dropped accordingly, from 0.9 tonnes of standard coal equivalent (tce) in 2000 to 0.6 tce in 2015. Freshwater consumption per tonne of steel produced also dropped sharply, from $30 \mathrm{cu}$ m to $3.3 \mathrm{cu}$ m over 2000-15. Finally, sulphur dioxide emissions dropped from $4.5 \mathrm{~kg} / \mathrm{t}$ in 2001 to $0.9 \mathrm{~kg} / \mathrm{t}$ in 2015 . 
The eruption of the GFC in 2008 marked an inflexion point for the Chinese economy. The worldwide economic slowdown reduced demand for China's exports at the same time as structural change within the Chinese economy was producing rising wages that were also eroding China's export competitiveness. In response, in 2009 China implemented a large-scale fiscal stimulus package that was effective in stimulating the economy for a while, but was ultimately unable to sustain the earlier role of fixed-asset investment in driving China's growth. The economic growth rate has fallen annually since 2012.

It was inevitable that the steel industry - a pillar of China's industrial and fixedasset investment sectors - would be adversely affected. In 2015, output of crude steel in China reached 804 million tonnes, reflecting a year-on-year fall of 2.3 per cent. This was the first production decline since 1982. The same year, China's apparent consumption of steel was 698 million tonnes, reflecting a year-on-year fall of 5.8 per cent.

The fall in steel production has inevitably also affected the prices of raw materials that are fundamental to steel production, such as iron ore and coking coal. Prices for steel and related materials, as well as industry profits, have decreased dramatically. In 2015, the 100 or so large steel enterprises with CISA membership — which together account for 76 per cent of crude steel output in China-achieved sales revenue of RMB2.9 trillion. This reflects a year-on-year fall of 19 per cent. Profits were, however, in negative territory, reaching minus RMB64.5 billion, of which losses attributable to steel businesses were more than RMB10 billion, and the share of loss-making enterprises was 51 per cent.

This is the background that has made it necessary to dramatically restructure the Chinese steel industry. The next section provides more discussion on how the problems associated with the steel industry have been created, due especially to the changing market environment as well as problems of stateowned enterprises (SOEs) in relation to governments. The section thereafter discusses reform issues.

\section{Market failures, homogeneous competition and poor industry performance}

Steel has been a central pillar of China's rapid growth story. It has, however, also been a source of problems, ranging from its adverse environmental impacts to problems associated with the continued dominance of the state sector. The latter is a core part of the restructuring strategy for the industry. Before discussing the reform of SOEs in restructuring, we first clarify the fundamental factors that are driving declining profits in the steel industry. 
Some of the challenges facing the steel industry have in recent years been attributed to its declining profits owing to the high price of imported iron ore (Liu 2013a). This is associated with the view that the three mining giants of BHP, Rio Tinto and Vale eroded the profit margins of the steel industry by taking advantage of their monopoly position (Hurst 2015). In general, however, the changing trends in the iron ore price and changes in CISA member profitability since 2000 appear to have little correlation. The iron ore price, for example, was below US $\$ 30$ per tonne from 2000 to 2003, while the profits of CISA members increased from nearly zero to about 7 per cent - a rate higher than the average levels of the manufacturing and mining industries across the same period. Moreover, after 2003, the iron ore price increased continuously until peaking at US\$190 per tonne monthly in 2011, while the profit rate of CISA members was retained within the normal range of 6-8 per cent (Figure 14.1). Since the economic slowdown, however, the iron ore cost, insurance and freight price has fallen continuously, to below US\$40 per tonne at the end of 2015. This is the equivalent of just one-quarter of the earlier peak price. The profitability of the steel industry has not improved, but has in fact incurred overall losses from an early base of low profits. This may suggest that rising iron ore prices are not directly related to falling profits in the steel industry.

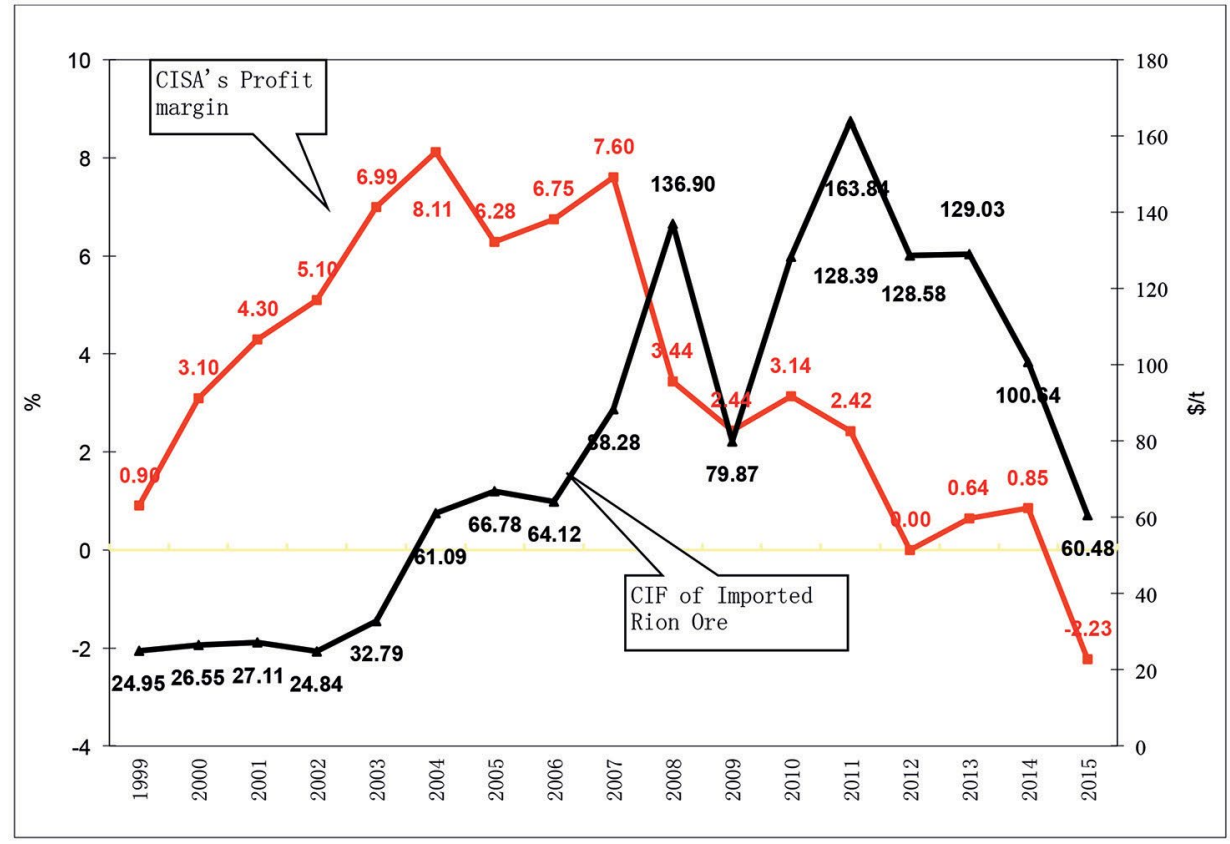

Figure 14.1 Changing profit margins of CISA members versus iron ore prices, 1999-2015 (per cent and US\$/t)

Sources: Data taken from CISA, China Customs. 
There is another view in industry circles that the reduction of demand and resulting excess capacity are the core drivers of declining steel industry profits (Liu 2013a). This view may not hold true, however, as within the same industrial environment, the profit rate of large enterprises lags far behind that of the small enterprises in the industry. Data from 2015 illustrate the point. Smelting and pressing processing enterprises for ferrous metals that are above the designated size ${ }^{1}$ realised profits of RMB52.6 billion at the same time as CISA members incurred total losses of RMB64.5 billion, with the latter accounting for some two-thirds of the total steel production in China (Table 14.3). This suggests that SOEs are responsible for a disproportionate share of financial losses in the steel industry.

Table 14.3 Profitability of steel enterprises

\begin{tabular}{|l|r|r|r|r|}
\hline & \multicolumn{2}{|c|}{$\begin{array}{c}\text { NBS: Smelting and pressing processing } \\
\text { enterprises for ferrous metals above } \\
\text { designated size (about 10,000 firms) }\end{array}$} & \multicolumn{2}{|c|}{$\begin{array}{c}\text { CISA members: 100 large and } \\
\text { medium-sized steel enterprises }\end{array}$} \\
\cline { 2 - 5 } & Total profits & Profit margin (\%) & Total profits & Profit margin (\%) \\
\hline 2012 & 1,229 & 1.73 & -7.6 & 0.00 \\
\hline 2013 & 1,695 & 2.22 & 228.86 & 0.64 \\
\hline 2014 & 1,647 & 2.20 & 304.44 & 0.85 \\
\hline 2015 & 52.55 & 0.81 & -645.34 & -2.23 \\
\hline
\end{tabular}

Sources: Data taken from CISA and NBS.

In an efficient and fully competitive market, fluctuations in raw material prices and final demand changes will be transmitted through the changes in the supply-demand relationship and resulting market prices. Steel products are an industrial necessity with extremely low demand elasticity. Changes in the demand volume are therefore unlikely to affect the supply-demand relationship much in a normal circumstance. The emphasis in dealing with such a relationship should be placed on adjustments to the supply side. In this view, the marginal producer plays a vital role in acting as an adjusting or regulating mechanism in influencing market outcomes. In responding to changes in the supply-demand relationship and in product prices, marginal producers will decide whether to enter into or suspend operations. If this type of regulating mechanism works smoothly and effectively, as in a free market system, the market allows for average profits that are just sufficient to keep firms operating efficiently, while inefficient firms will exit.

1 These enterprises, which were included in the national statistics, had annual sales income of RMB20 million or more. There were about 10,000 such enterprises at the end of 2014, including those engaging in further processing of steel. 
In a highly capital-intensive, continuous thermal energy consuming and mass employee-driven industry such as steel production, it is technically and socially difficult for the marginal producer to stop and start operations as readily as the logic of an economic model implies. In reality, there are certain obstacles to exit that make it difficult to replicate pure market conditions, as would be reflected by a near instant market-oriented self-readjustment or regulation.

In recent years in China's steel industry, the annual average losses of a number of enterprises have exceeded RMB1,000 per tonne. These losses, however, may be much higher if viewed in terms of monthly operations, and where each product type and order are examined. For some enterprises, the losses have even exceeded the sum of depreciation, wages and interest-yet these firms have continued production.

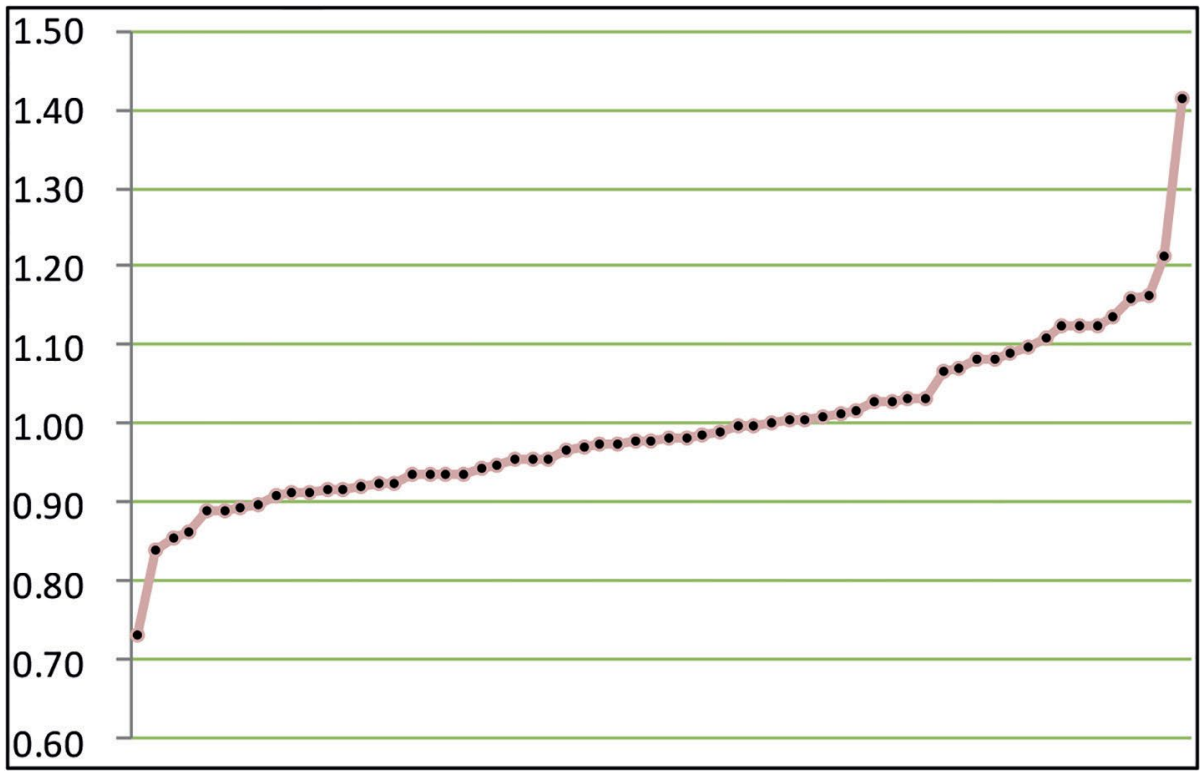

Figure 14.2 CISA members' cost rates, 2015 (cost of sales over total sales)

Note: The vertical axis represents cost of sales/total sales and the horizontal axis represents steel companies.

Source: Data taken from CISA, including only integrated steel mills.

Figure 14.2 indicates that the selling costs for almost half of the enterprises in China's steel industry exceeded their selling prices in 2015. In other words, their gross profits are negative. In addition to the costs of manufacturing, there are costs for pending sales, including general administration and financial expenses. Accounting for those additional costs would drive the ratio even higher for some firms. 
Assuming an effective market mechanism, the average price line (selling price/ selling cost) should approximate 1.2, as indicated in Figure 14.2. The average price line, however, just slightly exceeds 1.0 (the ratio is 1.0). The difference between the two is attributable mainly to the marginal producers who suffer losses but continue to produce anyway. Marginal producers - mostly large SOEs - drag down average industry profits by incurring huge losses. These firms also dump their excess production on to the market, pushing down steel prices and pulling up the prices of steelmaking inputs. ${ }^{2}$ This prevents more efficient firms from making normal profits. This is the basic situation confronting the steel industry. The solution is clear: inefficient enterprises must exit the market.

Another reason for the severe losses in the steel industry is homogeneous competition - that is, companies are producing similar products and compete with each other to sell them in the markets. There are some 500 enterprises with steel metallurgy capacity in China. In Hebei province, where one-quarter of the national steel capacity is based, there are 120 steel enterprises, many of which produce the same type of steel products. The market environment in which these firms operated changed in 2010, when the iron ore market worked around a long-term contract pricing mechanism.

Under the old model, especially in its later period, the long-term price contract system saw prices in general increase dramatically, but contracts were sold to different enterprises at different prices. In particular, large enterprises (typically SOEs) enjoyed privileged access to cheap long-term contracts or owned iron ore mines themselves, meaning their cost of acquiring iron ore was relatively low. Across the first half of 2008, the average price for imported iron ore for SOEs, for example, was RMB500 per tonne lower than that for small private enterprises, which were forced to buy more expensive iron ore at spot-market prices. This certainly constituted a very different cost curve for operators in China's steel market. On the other hand, although small and medium-sized enterprises produced steel with relatively higher material costs, these enterprises enjoyed some advantages, including lower labour costs, more flexible management and being more sensitive to market signals in that once they suffered a certain level of losses, they could suspend production or even exit the industry. In other words, if we assume that the steel industry is dominated by private enterprises, the market clearing mechanism will work more effectively, leading to a more efficient allocation of resources.

2 It should be noted that this type of overshoot may be common in capital-intensive industry - adjustment to changed market conditions takes time and does not go smoothly, even with all private players in a competitive market. 
The long-term contract pricing mechanism for iron ore ended in 2010, and since then the price has declined significantly. At the same time, China's commodities market has matured in the range of financial instruments available. China has, for example, successively developed a futures market, spot market and e-commerce systems for finished and semifinished steel products as well as for steelmaking raw materials, including iron ore, coking coal, coke and ferrous alloys. With these mechanisms in place, domestic steel producers enjoy more channels through which to buy raw materials. In addition, large steel mills no longer have access to cheaper iron ore. As a result, the cost difference for raw materials among different enterprises is shrinking and in some cases has even been eliminated. This situation has put enterprises on a more equal footing in terms of their cost competitiveness, especially between SOEs and private enterprises. On the competitive market, with more homogeneous steel products being produced and sold, all enterprises tend to take 'positive cash flow' as the shutdown point, meaning that all would suffer losses where losses arose. This is the background to the fact that the entire Chinese steel industry is making a loss at the moment.

\section{Market failures and the rigidity of SOEs' operations}

At present, within China's steel industry, a number of marginal producers are not responding to market signals and are not exiting the industry. These enterprises can in fact operate into the long term while making continuous losses. It is, however, impossible for them to do so without financial support from external sources, such as governments. This is especially the case for SOEs. Private enterprises, on the other hand, usually do not enjoy this kind of external support. They usually suspend production when their losses reach a certain level because they cannot sustain them. For example, when steel market product prices declined greatly in late 2015 , about 30 private steel enterprises in northern China suspended production, including a large steel mill named Songting Steel with annual output of 5 million tonnes. The extent of their losses was, in fact, far lower than that of some large SOEs, who continued production.

Three types of support enable SOEs to maintain production at a loss for a long time: 1) government subsidies; 2) support from a superior group of enterprises (through direct subsidy, interest-free loans or provision of loan guarantees); and 3) loans from a state-owned bank. These conditions have made SOEs much less sensitive to profit changes and other market signals. For example, when the market environment and profits deteriorated, these marginal producers became 'zombie enterprises' - firms that are reliant on external support for survival. Such enterprises have operational indicators that include long-term losses, 
no hope of stopping those losses and insolvency. Therefore, SOEs, with their rigid operating mechanisms, are in fact the main cause of market failures in the steel industry.

This view can also be demonstrated by comparison of the distribution characteristics of the rate of profit (sales) of 42 industrial and mining industries in China. For industries whose proportion of state-owned capital is low or close to zero, average selling profit rates are distributed intensively in the narrow range of 5-10 per cent (Figure 14.3). With increasing use of state-owned capital, the distribution of profit rates scatters. For example, the rates of profit for petroleum, mining and tobacco enterprises with a high degree of monopoly are higher than average, but industries with a high proportion of state-owned capital and no monopolistic position, such as ferrous and nonferrous metals and coking, have observably lower profit rates (Liu 2013b).

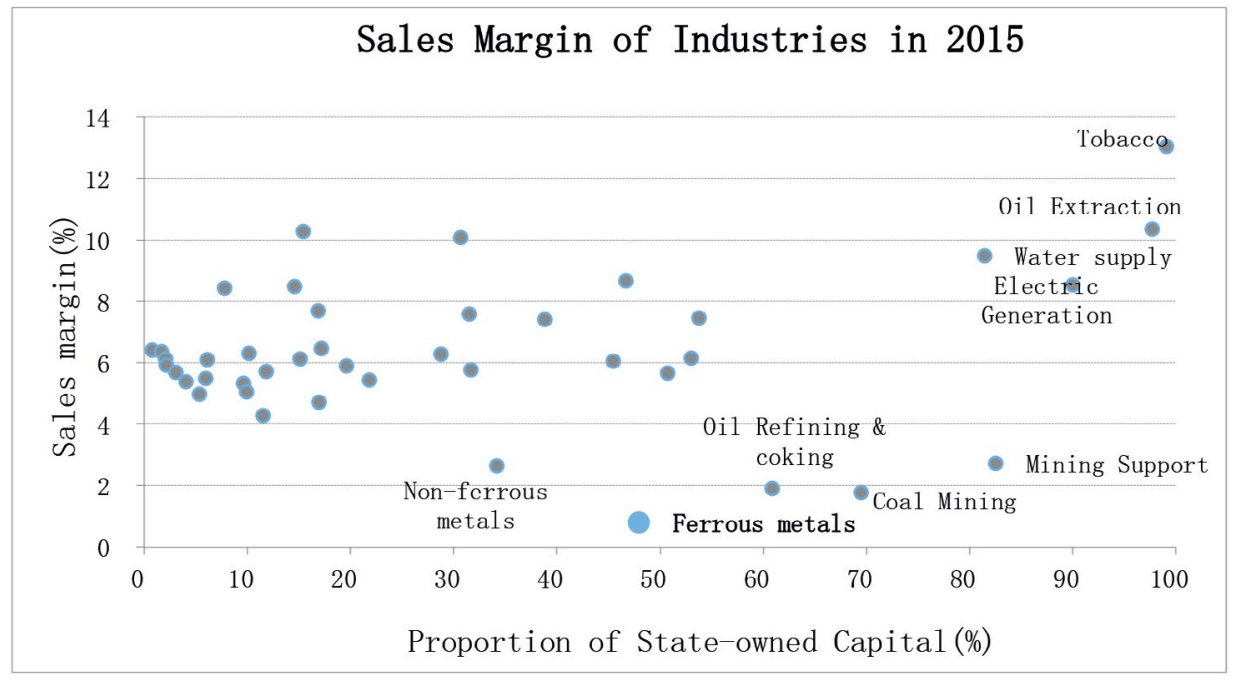

Figure 14.3 Sales margin versus proportion of state-owned capital, 2015 (per cent) Sources: Data taken from NBS.

The Chinese steel industry comprises SOEs and private enterprises. Until 2015, there were 27 large steel SOEs (including group companies that owned many steel mills). Their collective steel output was 353 million tonnes, which accounted for 44 per cent of China's total steel output. The remaining output is attributed to the more than 400 private steel mills (70 of them CISA members) whose steel metallurgy capacity accounts for the remaining 56 per cent of China's total steel output.

Although losses are happening across the board, data for the past few years indicate that losses are arising disproportionately within large enterprises, especially large SOEs. Among the top 10 enterprises with losses in 2015 , 
nine were SOEs (Liu 2015). Table 14.4 outlines descriptive data on the comparative performance of SOEs and private enterprises (that are CISA members) in the steel industry for 2015.

Table 14.4 Comparison of performance between SOEs and private enterprises, 2015 (RMB)

\begin{tabular}{|l|r|r|r|r|}
\hline & \multicolumn{1}{|c|}{$\begin{array}{c}\text { Profits on } \\
\text { steel business } \\
\text { (RMB billion) }\end{array}$} & $\begin{array}{c}\text { Loss per tonne } \\
\text { of finished steel }\end{array}$ & $\begin{array}{c}\text { General administration } \\
\text { per tonne of } \\
\text { finished steel }\end{array}$ & $\begin{array}{c}\text { Financial cost } \\
\text { per tonne of } \\
\text { finished steel }\end{array}$ \\
\hline Total & -77.9 & $\mathbf{1 7 7 . 2 7}$ & $\mathbf{1 0 2 . 2 8}$ & $\mathbf{9 8 . 1 0}$ \\
\hline SOE & -72.7 & 228.38 & 116.67 & 110.9 \\
\hline Private $^{*}$ & -5.2 & 42.69 & 64.37 & 64.40 \\
\hline
\end{tabular}

* Private enterprises here are only those which are CISA members.

Sources: Data taken from CISA.

The high cost of labour is one direct reason for the poor efficiency of SOEs. According to a 2014 survey of CISA members, the average steel output per worker for private steel enterprises is 514 tonnes per annum; for SOEs, it is just $270 \mathrm{t} / \mathrm{p}$.a. The average wage for an SOE steel mill worker (including social insurance) is RMB5,094 per month, which is 1.34 times that for a private enterprise employee, whose per capita wage is RMB3,807 a month. In other words, in SOEs, each tonne of steel incurs a RMB227 human cost-2.6 times greater than for a private enterprise, where the equivalent cost is only RMB89. Table 14.4 also shows that the total management cost per tonne of finished steel in SOEs is nearly double that of CISA members.

Complex organisational layering is a common problem among SOEs. Data disclosed by the media in recent years show that the actual number of staff in SOEs is often double the number required. For example, at a forum held in Taiyuan, capital of Shanxi province, on 23 February 2016, at which Chinese Premier Li Keqiang was a speaker, the President of Taiyuan Steel Co. Ltd reported to the Premier that there were 50,000 employees in his enterprise, but only 20,000 were needed. Later, Wuhan Steel Group declared that it planned to reduce staff numbers from 80,000 to 30,000 employees, on the basis of maintaining the original production scale. Anshan Steel Group, the oldest steel enterprise in China, also plans to reduce its 160,000-strong workforce to about 100,000 .

Not only are SOEs planning to downsize, but there is also a trend in the industry towards a greater share of output being produced by the private sector (Figure 14.4). Specifically, the share has risen from only 9.8 million tonnes in 2000, accounting for just 7.7 per cent of the nation's total steel output in that year, to 450 million tonnes in $2015-56$ per cent of total steel output. 


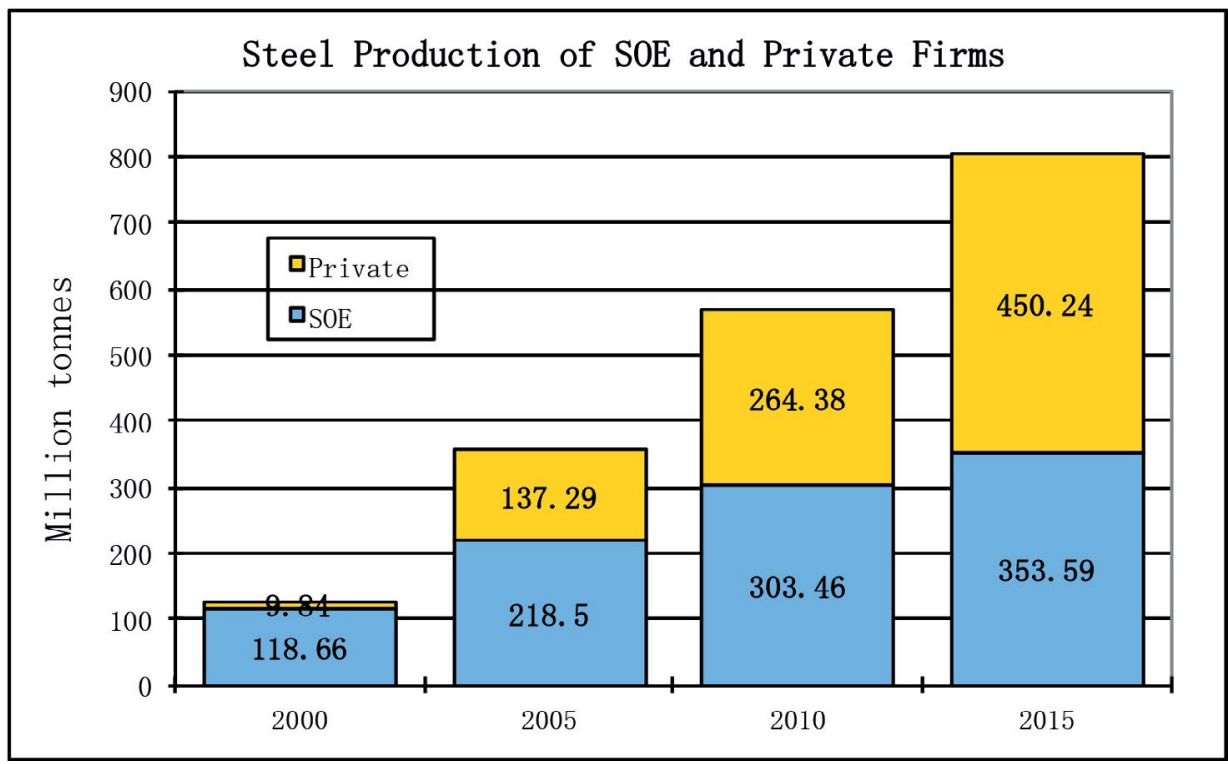

Figure 14.4 Comparison of SOE and private enterprise steel production, 2000-15 (million tonnes)

Sources: Data taken from CISA and NBS.

The rising role of private steel enterprises in the industry can be attributed to two factors, the first of which is privatisation of SOEs. Firms that were once stateowned but are now in private hands include Nanjing Steel Co. Ltd, Pingxiang Steel Co. Ltd, Nanchang Steel Co. Ltd, Jiyuan Steel Co. Ltd and Fushun Steel Co. Ltd. The second factor is the expansion in scale of newly built, privately owned and run enterprises (Liu 2015).

Nationally, the Chinese Government has issued a plan that will encourage a decline in steel production capacity from 150 to 100 million tonnes over the next five years. It is estimated that 500,000 workers from the industry could lose their jobs under the plan. Given that enterprises that will retain current capacity might still reduce their workforce, the actual number of workers losing their jobs could be even higher. The province of Hebei will be especially affected.

Despite several rounds of enterprise reform carried out in the past (Song 2015), the problem of redundancies associated with SOEs remains a key outstanding issue. If SOEs had employed workers according to need in the past 10 years, the task of reallocating workers from the industry may not present as dramatically as it now does, but a policy of 'securing jobs' has been deeply entrenched in the running of SOEs. Leaders of SOEs as well as local governments have tended to tolerate losses rather than risk dismissing staff, which would generate an 
alternative - and noisier - problem on the social front. Moreover, there is a pervasive view that not dismissing staff assumes social responsibility, justifying loss-making conformity under the banner of the equity principle.

The second reason for the poor efficiency of steel SOEs is their heavy debt burden. It can be seen from Table 14.4 that the financial cost assumed for each tonne of steel in an SOE is nearly twice that for private enterprise. On the surface, this could appear to be inconsistent with the idea that it is easier for SOEs than for private companies to gain low-interest loans from state-owned commercial banks. In fact, this is precisely the reason why SOEs tend to accumulate more debt-because they face 'soft budget constraints'. In turn, SOEs in China's steel industry have, year after year, suffered heavy financial losses.

A third reason for the poor efficiency of SOEs is that compared with private sector firms, SOEs face a relatively high level of direct and operational intervention by local government. Owing to the structure of China's government performance examination, local officials are highly motivated to increase tax revenues, expand employment and maintain social stability. When the demand for steel was high, local governments rushed to develop their own steel industry without paying much attention to environmental protection, geographical location or product quality. This led to the rapid expansion of steel production capacity in the SOE sector, in spite of repeated Central Government orders to reduce the scale of steel production.

The fourth political economy explanation for poor steel industry efficiency also has an economic geography component. Among large steel enterprises incurring heavy financial losses, a disproportionate share is located in China's inland areas, where access to raw materials such as iron ore means depending almost entirely on imports. And, compared with Chinese provinces that are proximate to seaports such as Hebei, inland industries must then have the imported materials freighted by domestic railway, ship or road transportation. And, not only are these steel mills paying more for inputs, but also their steel production usually outstrips local demand, meaning some of these producers sell more than half of their product back to China's more economically dynamic coastal regions - sales that again involve high transportation costs. Such enterprises are unlikely to have the capacity to make a profit even if their management is very efficient.

Such SOE-led market failures have had industry-wide and also upstream and downstream effects, and so far the industry has been incapable of overcoming the disadvantage of homogeneous competition. The main reason for this is that the operational purpose of SOEs and of private enterprises is fundamentally different. Private enterprises are pursuing maximum returns on capital, while SOEs hold on to the value derived when 'everyone has a secure job'. In seeking mergers and industry reorganisation, it has been difficult to align these worlds. 
It has also been difficult to realise the so-called mixed ownership model sought by the government. Another reason is the negative impact on firms' financial positions as a result of reorganisation among SOEs. When a competitive enterprise merges with an uncompetitive one, the former immediately bears the burden of providing support to the latter, often over an extended period. The scale of the challenges adopted by competitive steel industry firms in merging with uncompetitive firms means that the concentration ratio of the Chinese steel industry has never realised the targets set by various plans and industrial policies (Liu 2015). On the contrary, the concentration has been in decline (Figure 14.5).

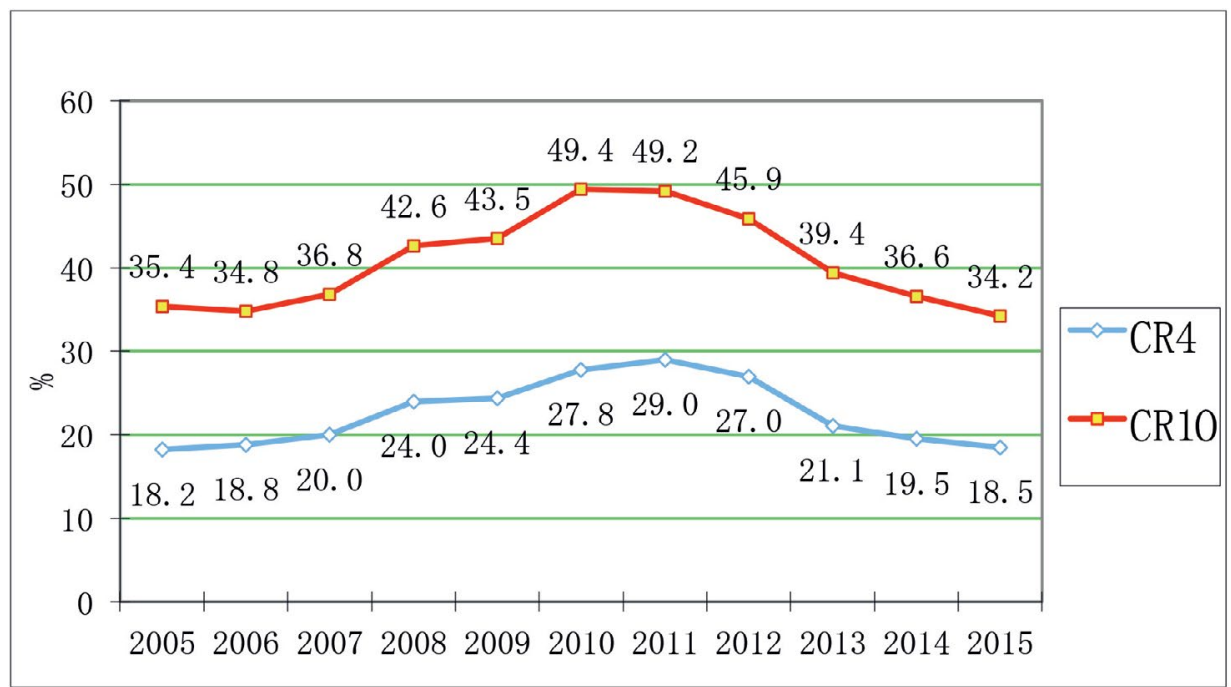

Figure 14.5 Concentration ratio of the steel industry, 2005-15 (per cent)

Note: CR4 and CR10 stand for the ratios of top 4 and top 10 companies' output to total outputs respectively.

Sources: Data taken from CISA and NBS.

\section{The outlook for the reform and restructuring of China's steel industry}

First, a factor that will inevitably and significantly shape steel industry dynamics in coming years is the reality that China's steel consumption appears to have passed its peak. Specifically, 2013 was the highest year by far of apparent steel consumption. That year, 772 million tonnes were demanded-equivalent to $569 \mathrm{~kg}$ per capita and more than twice the world average $(234 \mathrm{~kg})$ for that year. In 2014 and 2015, China's steel consumption per capita decreased annually, by 4.6 and 5.9 per cent respectively. 
As Figure 14.6 shows, however, China's per capita steel consumption remains above the world average, at $511 \mathrm{~kg}$ for 2015-placing China above most developed countries in North America and the European Union. Interestingly, China's consumption levels are roughly comparable with those of high-end industrial manufacturers, such as Germany and Japan, and still lower than those of smaller but developed industrial countries such as South Korea and the Czech Republic (Figure 14.6).

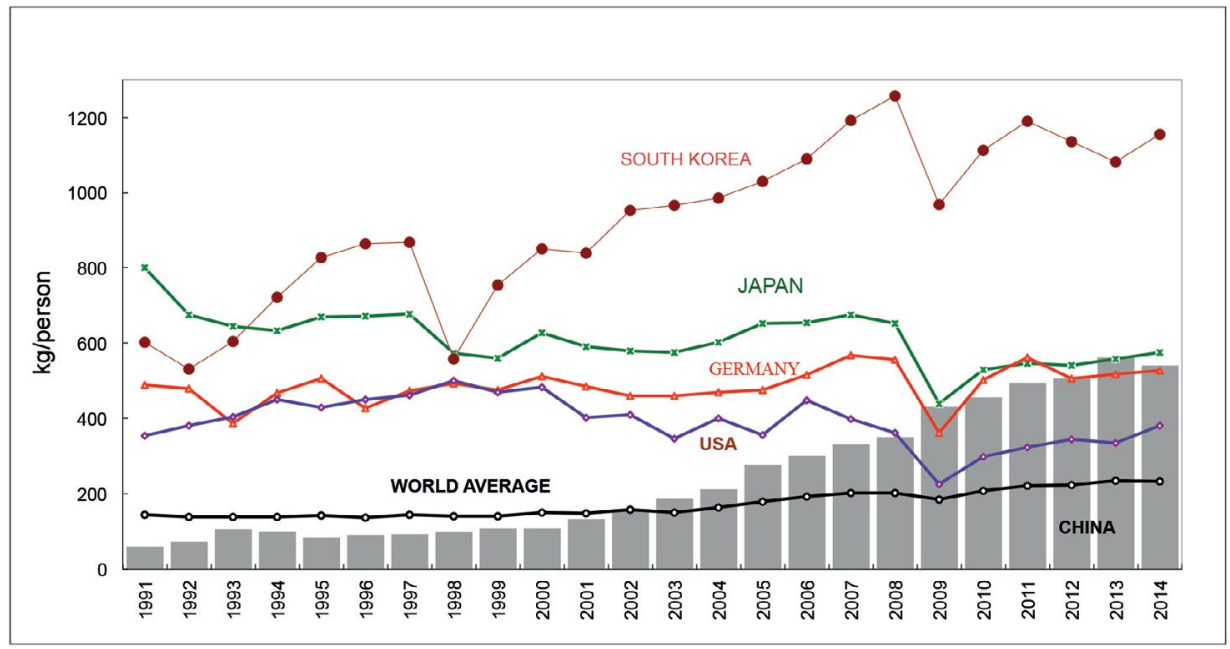

Figure 14.6 Apparent steel use per capita of major economies, 1991-2014 (kg per person)

Source: World Steel Association (2005-15).

Historical experience shows that steel consumption in most industrialised countries follows the 'life cycle' steel industry rule: its trajectory often has a strong correlation with the economy's development stage, speed of growth, economies of scale and domestic industrial structure. The United States, Japan and France reached their peak levels of per capita steel consumption of $711 \mathrm{~kg}$, $802 \mathrm{~kg}$ and $485 \mathrm{~kg}$, respectively, in 1973. Germany's peak arrived a few years earlier, in 1970, when per capita steel consumption reached $660 \mathrm{~kg}$.

Researchers of China's steel industry and foreign research institutions have for some years been trying to forecast China's own 'peak' steel consumption level. Studies have forecast that China will complete its industrialisation by about 2020 and total steel consumption will then peak at 0.8 to 1 billion tonnes (McKay et al. 2010). As steel consumption has fallen along with the slowdown in the economy in the past two years, some observers have suggested that China has already reached peak steel consumption, in 2013, and that declines will continue for some years. Others, however, disagree with this conclusion (Liu 2016). 
The average of these views means that, at best, there will be limited if any room for further growth in steel consumption in China. Some analysts, however, believe that China's steel consumption will stay on a 'high platform' for a long time (Xu 2016). This will depend on the industrial path that China's economy takes in the years ahead. For example, despite the negative impact of the GFC on selective industrialised economies, steel consumption has remained continuously high over a long period. In South Korea, consumption even appears to have significantly increased with per capita steel consumption reaching $1,113 \mathrm{~kg}$ in $2015 .^{3}$ Considering that China has not yet completed its industrialisation, its gross domestic product (GDP) per capita was less than US\$8,000 in 2015 and the urbanisation rate had reached only 56 per cent in the same year, it seems China still has some distance to go before reaching the industrialisation levels of a developed country. It is therefore difficult to confidently predict the direction of the steel industry.

Also, importantly, average national statistics for China hide the great imbalance in economic development across the country. In first-tier cities such as Beijing, Shanghai, Tianjin and Guangzhou's frontier city of Shenzhen, GDP per capita stands at about US\$17,000. For several of China's less-developed provinces, however, GDP per capita was just over US\$4,000 in 2015. Such an unbalanced pattern enables the steel consumption curve to change in a gradual fashion. This will necessitate managing the previously mentioned geographic cost factors attached to inland steel production.

Thanks to modern technical gains that may reduce metal intensities in further industrialisation, China may never reach the historical per capita steel consumption peaks of the United States and Japan. But, owing to the factors discussed herein, we predict that for the time being there will be a relatively slow and incremental decline in consumption. At the same time, one cannot rule out the possibility for China to reach a new peak in steel consumption on per capita terms in future. First, the efficiency gains resulting from the current economic rebalancing and restructuring could generate new impetus for growth and thus demand for steel consumption. Second, the economic catching up by those inland regions could generate new demand for steel products. Third, China may increase its exports of those goods that have high metal intensities such as machinery and automobiles in the future. ${ }^{4}$

Second, measures adopted by the Central Government to limit total steel production capacity may not be effective in the short term. In turn, the problem of overcapacity could persist for some time. In recent years, the Central Government has repeatedly called for the expansion of new steel production

3 World Steel Association, 2016.

4 China's 'One Belt and One Road' strategy could be another factor in increasing future demand for steel. 
capacity to be limited. New steelmaking projects, such as Baosteel's project in Zhanjiang, WISCO's Fangchenggang project and the Shandong Steel Group project in Rizhao, have required investors to prove the principle of 'equal or decrement replacement'. This means they have to close an equal or greater amount of existing and less technically advanced capacity before being allowed to operationalise new facilities.

In general, however, there is much uncertainty about whether such principles are being adhered to. It is difficult for the Central Government to effectively monitor big industry when there are hundreds of steel mills. Existing competitive enterprises may, for example, expand their production capacity by replacing smaller furnaces with bigger ones. Local governments benefit from the capacity expansion and have little incentive to limit their investments in steel capacity. For these reasons, it may be reasonable to fear that excess steel capacity in China will not change significantly regardless of future steel consumption levels.

Third, SOE reforms necessitate fundamentally changing the management and governance systems and operating mechanisms of these enterprises. Helping the Chinese steel industry to exit its 'winter' is not simply a matter of adjusting the supply and demand imbalance, but also requires solving the problem of market failure (or, to a great extent, 'government failure') by ensuring that SOEs become truly competitive in the steel market. This transition will take time and will depend on how fast the general package of market-oriented reforms also shifts the broader economy.

The story is not, however, entirely bleak. There are some favourable factors for achieving reform targets sooner than expected. First, there exist superior SOE and state-owned bank 'group companies' within local governments. These have been suffering from the endless transfer of finance to 'zombie enterprises' and are therefore eager for a change to the status quo. Second, zombie enterprises that have accrued heavy debts or have become insolvent may not survive long without external support, and therefore may have no choice but to finally exit the market. Third, the Central Government has arranged tens of billions of renminbi in funds to solve the unemployment problems that will be caused by removing zombie enterprises from the steel market.

These challenges and the need for change arise within a complex broader environment of political economy reform - for example, the question of how to address the contradiction between the special political status (or privileges) of SOEs and the principles of fair market competition. There is so far no established guiding principle for solving this contradiction, and the experience of other large economies transitioning to large-scale privatisation shows this problem should be approached with care. How to ensure SOEs practise effective selfgovernance is another unresolved challenge that ultimately hinges on how 
much the government is willing to overhaul the relationship between the state and markets. There are no certain solutions to these problems, but the sheer scale of loss-making by some SOEs has become financially unsustainable. It is estimated that some firms will need to exit the industry permanently and some will likely be privatised through merger and acquisition (M\&A) or by selling assets to private enterprises.

In turn, M\&A activities in the industry may be expected to accelerate as the reform program deepens. The declining net assets of disadvantaged enterprises provide opportunities for mergers and reorganisation at low cost for more competitive enterprises. Local governments and shareholders of loss-making enterprises are increasingly less likely than previously to resist M\&A. Steel industry market concentration is therefore expected to increase greatly in coming years. By restructuring within and between domestic regional markets, a monopolistically competitive market structure can be formed within the steel industry. The resulting curbing of the price war will be the main means of enhancing competition and also of deepening product division and improving the quality and profitability of the steel industry as a whole. As a result, the industry in the medium term is expected to recover to a normal level of profitability.

\section{References}

China Custom Statistics (various years), China Custom, Beijing, China. Available at: china-trade-research.hktdc.com/business-news/article/Fast-Facts/ChinaCustoms-Statistics/.

China Iron and Steel Association (CISA) Statistics (various years), China iron and Steel Association, Beijing, China.

Hurst, L. (2015), China's impact on global iron ore market, PhD thesis, Crawford School of Public Policy, The Australian National University, Canberra.

Liu, H. (2013a), Analysis and suggestions on the lower profitability of China's steel industry, China Steel, 2013(10): 11-18.

Liu, H. (2013b), Looking for the antidote to the excess capacity in the steel industry, China Metallurgical News, 20 June.

Liu, H. (2015), How to break the deadlock of M\&A in China's steel industry, China Metallurgical News, 10 June.

Liu, H. (2016), Demand side, supply side: The key is to reform supply side, China Steel Focus, 2016(1): 34-36. 
McKay, H., Sheng, Y. and Song, L. (2010), China's metal intensity in comparative perspective, in R. Garnaut, J. Golley and L. Song (eds), China: The next twenty years of reform and development, 73-98, Canberra and Washington, DC: ANU Press and Brookings Institution Press.

National Bureau of Statistics (NBS) (2015), China statistical yearbook 2015, Beijing: China Statistics Press.

Organisation for Economic Co-operation and Development (OECD) (2016), Excess capacity in the global steel industry and the implications of new investment projects, Paris: OECD. Available from: oecd-ilibrary.org/docserver/download/ 5js65x46nxhj.pdf?expires $=1463020168 \& \mathrm{id}=\mathrm{id} \&$ accname $=$ guest\&checksum $=$ A59B9DA06B0EA68A8DF241517C7A35B0.

Sanderson, H. 2015, China steel exports climb over 100m tonnes, The Financial Times, 9 December. Available from: ft.com/intl/cms/s/0/7700d728-9e8f-1 le58cel-f6219b685d74.html\#axzz48c9W7m5j.

Song, L. (2015), State and non-state enterprises in China's economic transition, in G. C. Chow and D. H. Perkins (eds), Routledge handbook of the Chinese economy, 182-207, London and New York: Routledge.

Song, L. and Liu, H. (2012), Steel industry development and transformation in China: An overview, in L. Song and H. Liu (eds), The Chinese steel industry's transformation: Structural change, performance and demand on resources, 1-16, Cheltenham, UK: Edward Elgar.

World Steel Association (2005-15 [yearly issues]), Steel Statistical Yearbook, Brussels: World Steel Association.

World Steel Association (2016), Steel Statistical Yearbook, Brussels: World Steel Association.

$\mathrm{Xu}, \mathrm{X}$. (2016), Will China's steel consumption substantially drop after reaching the peak level?, China Metallurgical News, 2 March. 
This text is taken from China's New Sources of Economic Growth: Reform, resources and climate change, Volume 1, edited by Ligang Song, Ross Garnaut, Cai Fang \& Lauren Johnston, published 2016 by ANU Press, The Australian National University, Canberra, Australia. 